\title{
1. International climate change treaty regime
}

\section{Katrina Fischer Kuh}

The chief product of over 25 years of international negotiations to address climate change, the Paris Agreement, can be summarized in one sentence: Most countries in the world have agreed to set their own targets for reducing emissions, report on their progress toward meeting those targets using agreed-upon metrics, and update those targets and make them more stringent as necessary over time. The procedural requirements involved (tracking and reporting on emissions, setting and submitting targets) are binding, but there are no binding substantive requirements in the sense that countries may choose their own targets and there is no formal penalty for failing to meet a target. Stripped of its terms of art- "nationally determined contributions," "global stocktakes"- the contours of the Paris Agreement reveal themselves to be rather simple and modest, belying the lengthy and difficult negotiations that produced them. That the core requirements of the Paris Agreement are simple and modest does not mean that they will not ultimately prove effective. The simplicity and modesty of the core provisions of the Paris Agreement does, however, evidence the continued and primary importance of individual country commitments and measures to mitigate climate change; signal that the Paris Agreement's implementation and evolution will be crucial to whether and to what extent it ultimately adds value to worldwide mitigation efforts; and invite the question of why it took 25 years to achieve an agreement of such limited scope.

This chapter will begin by explaining terms, concepts, and the role of institutional actors central to the international climate change treaty regime. It will then describe key components of the Paris Agreement, highlighting how it centers domestic mitigation laws and explaining why the Paris Agreement's ultimate contribution to mitigation cannot be predicted with confidence. The chapter will conclude by looking back and summarizing the international climate change negotiations and agreements that preceded and produced the Paris Agreement, emphasizing issues and developments that help to explain its provisions and bottom-up approach. 
Periodic assessment reports summarizing the science related to climate change published by the Intergovernmental Panel on Climate Change (IPCC), an entity formed in 1988 by the World Meteorological Organization and United Nations Environment Programme, guide countries in the negotiation and implementation of international agreements to address climate change. ${ }^{1}$ IPCC reports engage the efforts of thousands of scientists around the world - the fifth assessment report involved 830 lead authors and review editors, over 1,000 contributors, and 2,000 expert reviewers from more than 80 countriesand are widely regarded as reliable and authoritative statements of scientific knowledge regarding the causes and impacts of climate change. ${ }^{2}$ Reflecting the emerging nature and uncertainties of climate change science, assertions within IPCC reports are often accompanied by a characterization of the level of confidence for the assertion, which can range from very high confidence to very low confidence. Where an assessment of confidence is not possible, a description of the level of agreement and evidence that supports an assertion may be provided instead. In addition to detailed scientific and technical analysis, IPCC reports include a Summary for Policymakers which provides a more accessible overview of the most salient information in the report. Unlike full-length report chapters (which must be accepted by a plenary session that includes government representatives but which are not subject to editing by government representatives), the Summary for Policymakers is a consensus document subject to review and revision by governments and as a result tends to represent middle ground. Critiques of the IPCC process and the reports that it produces include that they do not adequately incorporate feasibility issues and understate worst-case risk.

The international climate treaty regime that the IPCC reports inform consists of three core agreements: the United Nations Framework Convention on Climate Change (UNFCCC) (1992), ${ }^{3}$ Kyoto Protocol (1997), ${ }^{4}$ and Paris

\footnotetext{
1 Reports of the IPCC are available from the IPCC's website at https://www.ipcc .ch/ (last visited March 1, 2021).

2 For an overview of the development and work of the IPCC, see UNION OF Concerned Scientists, The IPCC: Who Are They and Why Do Their Climate REPORTS MATTER? (July 2018), available at https://www.ucsusa.org/resources/ipcc -who-are-they (last visited March 2, 2021).

3 United Nations Framework Convention on Climate Change, May 9, 1992, S. Treaty Doc No. 102-38 (1992), 1771 U.N.T.S. 107 [hereinafter UNFCCC].

4 Kyoto Protocol to the United Nations Framework Convention on Climate Change, Dec. 11, 1997, 2303 U.N.T.S. 162 [hereinafter Kyoto Protocol].
} 
Agreement $(2015)^{5}$ - the key provisions of which are described below. Decisions further elaborating on and implementing these agreements are made by a conference of the parties (COP). Over time, these COPs have evolved from government-centered negotiations to massive gatherings that include states, intergovernmental organizations, and a diverse array of nongovernmental organizations (NGOs), climate change activists, academics, and representatives from the private sector. Recognized constituencies (groups of NGOs with diverse but broadly clustered interests or perspectives) include business and industry NGOs (BINGOs), environmental NGOs (ENGOs), farmers and agricultural NGOs (Farmers), indigenous peoples organizations (IGOs), local government and municipal authorities (LGMAs), research and independent NGOs (RINGOs), trade union NGOs (TUNGOs), the women and gender constituency (WGC), and youth NGOs (YOUNGOs). At modern COPs, formal proceedings and state-level negotiation are embedded in a rich milieu of workshops, side events, exhibits, and meetings.

The most significant tension in the international climate change negotiations is whether and how climate change agreements should reflect the relative responsibilities of countries in light of differences with respect to countries' contribution of emissions, relative development and wealth, and vulnerability to the impacts of climate change. Discerning those responsibilities is central to setting expectations with respect to the speed and extent of emission reductions by a country and the support to be provided or received by a country for mitigation and adaptation efforts. There are different perspectives for evaluating responsibility. With respect to thinking about relative responsibility vis à vis contribution to the problem (emissions), country emissions can be viewed through the lens of a country's historical or cumulative emissions, current total emissions, per capita emissions (i.e., emissions as compared to population), and through the lens of production-based accounting (emissions physically generated within a country, including producing goods that it then exports) versus consumption-based accounting of emissions (which charges the emissions associated with a good to the country where the good is ultimately consumed). To take one example, India has significant current emissions but has relatively low historical and per capita emissions and, because it exports carbon-intensive goods to other countries, lower emissions under a consumption-based accounting approach. ${ }^{6}$ The charts shown in Figures 1.1

5 Paris Agreement to the United Nations Framework Convention on Climate Change, Dec. 13, 2015, in Rep. of the Conference of the Parties on the Twenty-First Session, U.N. Doc. FCCC/CP/2015/10/Add.1, annex (2016) [hereinafter Paris Agreement].

6 The different emission profiles of countries using these approaches can be found at: Hannah Ritchie, Who has contributed most to global CO2 emissions? OUR WORLD IN DATA (Oct. 1, 2019), https://ourworldindata.org/contributed-most-global-co2. 
and 1.2 give a sense of the differences as between countries with respect to carbon dioxide emissions as between countries with respect to cumulative and annual carbon dioxide emissions.

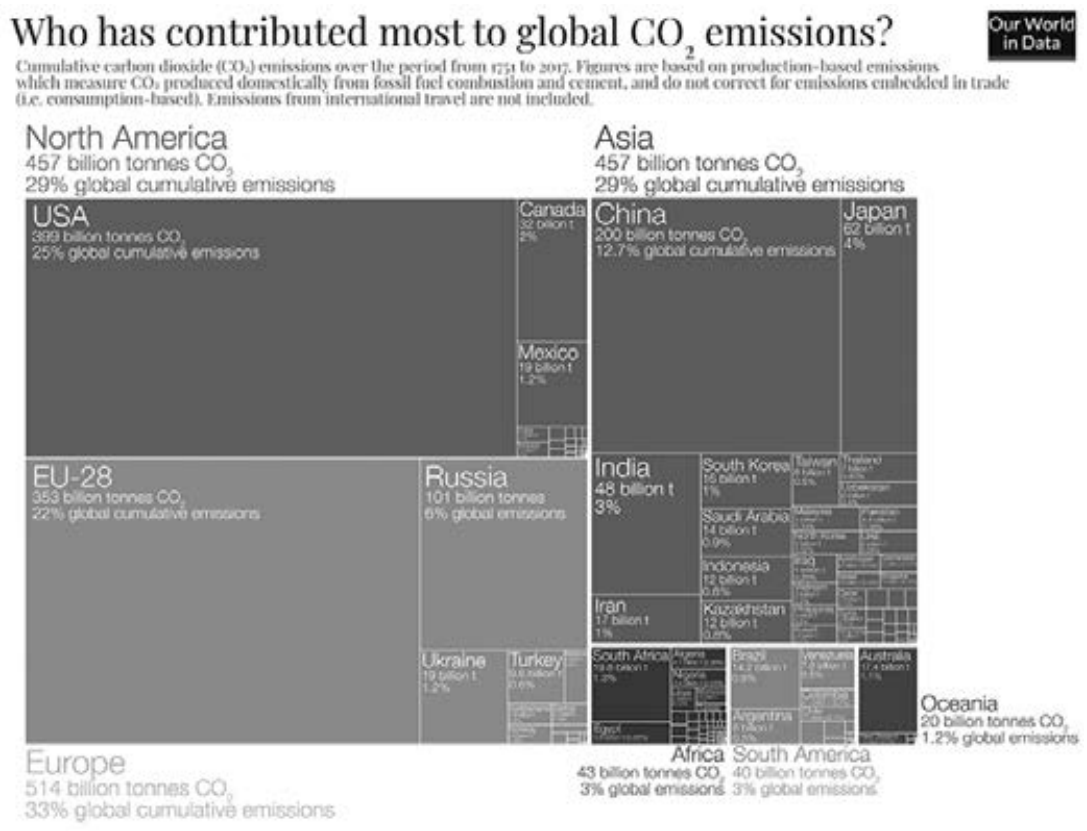

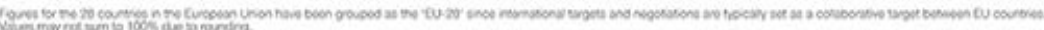

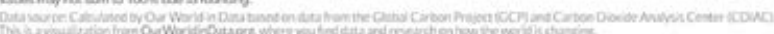

Figure 1.1 Who has contributed most to global CO2 emissions?

Hannah Ritchie, Who has contributed most to global CO2 emissions? OUR WorLD IN DATA (Oct. 1, 2019). Source: https://ourworldindata.org/contributed-most-global-co2.

Many countries in the Global North have high historical and current emissions, particularly when considered on a per capita basis, and the impacts that these countries face from climate change are, on the whole, projected to be later-occurring and less severe (at least initially). Many countries in the Global South have far lower historical and current contributions of emissions, particularly when considered on a per capita basis, but the impacts that these countries face from climate change are, on the whole, projected to occur sooner and be more severe. Countries in the Global North also tend to have, as a result of their wealth, greater capacity to adapt to the impacts of climate change than countries in the Global South. Additionally, historical emissions from the 


\section{$2018 \mathrm{CO}_{2}$ Emissions per Country from Fossil Fuel Combustion}

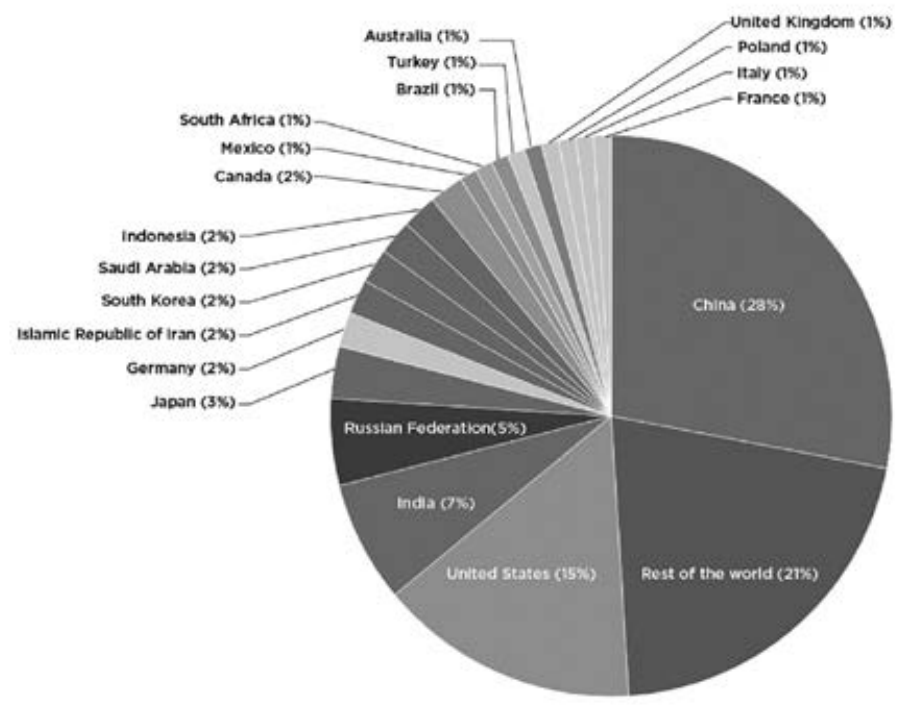

Figure 1.2 Each country's share of CO2 emissions

Each Country's Share of CO2 Emissions, UniOn OF CONCERnED SCIENTISTS. Source: https:// www.ucsusa.org/resources/each-countrys-share-co2-emissions (last updated Aug. 12, 2020).

Global North were chiefly produced during and as a result of industrialization; many countries in the Global South are still in the process of development and industrialization. As discussed in greater detail in Chapter 6, climate change thus presents a circumstance of markedly unequal burdens and unequal blame.

The international climate change regime has, from its inception, recognized both that the nature of climate change compels participation by all countries and that the Global North bears special responsibility and should take a leading role. Navigating these two principles to determine what, exactly, should be expected from different countries has, however, proved enormously difficult and the structure of the Paris Agreement reflects that difficulty. 


\section{OVERVIEW OF THE PARIS AGREEMENT}

The Paris Agreement embodies the current state of international cooperation with respect to climate change. An overview of key components of the Paris Agreement follows. Importantly, the Paris Agreement does not include topdown binding requirements for parties to reduce emissions, instead leaving parties with the freedom to determine their own mitigation goals while mandating processes designed to nudge or persuade countries to achieve responsible levels of mitigation over time. This bottom-up structure centers domestic adoption and implementation of mitigation measures.

\section{A The Temperature Goal}

The Paris Agreement announces as a key aim "[h]olding the increase in the global average temperature to well below $2^{\circ} \mathrm{C}$ above pre-industrial levels and pursuing efforts to limit the temperature increase to $1.5^{\circ} \mathrm{C}$ above pre-industrial levels." ${ }^{\prime 7}$ The temperature goal provides an important benchmark for evaluating the sufficiency of global commitments to reduce emissions, allowing for comparison of the emissions reductions required to meet the temperature goal as compared to projected emissions. For over 15 years, international climate change negotiations proceeded without a clear temperature goal, indexing mitigation efforts to the somewhat nebulous aim of stabilizing greenhouse gas (GHG) concentrations at a level that would prevent dangerous anthropogenic interference with the climate system. In 2010, countries identified a long-term goal of limiting the global average temperature increase to below $2^{\circ} \mathrm{C}$ above pre-industrial levels; adoption of the more ambitious goal of limiting warming to well below $2^{\circ} \mathrm{C}$ and pursuing efforts to limit warming to $1.5^{\circ} \mathrm{C}$ is often identified as a signature achievement of the Paris Agreement.

Meeting the Paris Agreement's more aspirational $1.5^{\circ} \mathrm{C}$ temperature goal, however, seems increasingly out of reach. As of this writing and as discussed in greater detail below, the gap between the emissions reductions presently called for under the Paris Agreement and the reductions necessary to avoid even $2^{\circ} \mathrm{C}$ of warming is startlingly large, somewhere in the range of 15 gigatons of carbon dioxide equivalent by $2030 .{ }^{8}$ Many knowledgeable observers concede that it is unrealistic to expect that the world will limit warming to 
anything close to $1.5^{\circ} \mathrm{C}$, with much steeper increases in temperature likely. ${ }^{9}$ The Paris Agreement's $1.5^{\circ} \mathrm{C}$ temperature goal may thus end up serving less as a meaningful goal and more as testament that mitigation efforts will not avoid significant climate change impacts, with devastating consequence.

The Paris Agreement's exhortation to limit warming to $1.5^{\circ} \mathrm{C}$ resulted in large measure from the advocacy of small island developing states (SIDS), organized as the Alliance of Small Island States (AOSIS), who are extremely vulnerable to climate change impacts. ${ }^{10}$ These countries, in addition to being unusually vulnerable to climate change impacts (often because of geography compounded by lack of adaptive capacity), have also contributed diminishingly little to climate change. They are least to blame yet will be first (and perhaps most severely) to suffer, giving their voice outsized moral force and influence in the international climate change negotiations. Since 2008, AOSIS actively championed the more ambitious mitigation target of $1.5^{\circ} \mathrm{C}$ and supported the development of relevant scientific data as well as working to push that data into the international climate change negotiations. Employing the rallying cry " $1.5^{\circ} \mathrm{C}$ to survive," AOSIS worked to persuade other countries, including other vulnerable countries and least developed countries, to support the $1.5^{\circ} \mathrm{C}$ temperature goal. Ultimately, a broad coalition of countries, including the "high ambition coalition" of developed and developing states, embraced the $1.5^{\circ} \mathrm{C}$ temperature goal during the negotiations and succeeded in enshrining it in the Paris Agreement.

In further support of the $1.5^{\circ} \mathrm{C}$ temperature goal, the decision adopting the Paris Agreement invited the IPCC to produce a special report on the impacts of global warming of $1.5^{\circ} \mathrm{C}$ above pre-industrial levels and related global GHG emission pathways. ${ }^{11}$ The IPCC's report, Global Warming of $1.5^{\circ} \mathrm{C}$ : An IPCC Special Report, documents how warming of $2^{\circ} \mathrm{C}$ would generate significantly more dire impacts than warming of $1.5^{\circ} \mathrm{C}$. Importantly, however, it also documents that even warming of $1.5^{\circ} \mathrm{C}$ would produce significant climate change impacts, particularly for SIDS, including impacts that could not be avoided through adaptation. ${ }^{12}$ The report explains, for example, that while " $[\mathrm{m}]$ arine

\footnotetext{
9 J.B. Ruhl \& Robin Kundis Craig, $4^{\circ}$ Celsius, 106 Minn. L. Rev. (forthcoming 2021).

${ }_{10}$ For an overview of AOSIS and its crucial role in the adoption of a $1.5^{\circ} \mathrm{C}$ temperature goal in the Paris Agreement, see Lisa Benjamin \& Adelle Thomas, $1.5^{\circ} \mathrm{C}$ to stay alive? AOSIS and the long-term temperature goal in the Paris Agreement, IUCN ACADEMy of ENVIRONMENTal LaW EJournal 7, (2016) 122-129.

11 Conference of the Parties on its twenty-first session, Part two: Action taken by the Conference of the Parties at its twenty-first session $921 \mathrm{FCCC} / \mathrm{CP} / 2015 / 10 /$ Add.1 (Jan. 29, 2016) [hereinafter Decision Adopting the Paris Agreement].

12 Intergovernmental Panel on Climate Change, Global Warming of $1.5^{\circ} \mathrm{C}$ : An IPCC Special Report on the impacts of global warming of $1.5^{\circ} \mathrm{C}$ above pre-industrial
} 
systems and associated livelihoods in SIDS face higher risks at $2{ }^{\circ} \mathrm{C}$ compared to $1.5^{\circ} \mathrm{C}$, " the impacts on coral reefs are extremely concerning at $1.5^{\circ} \mathrm{C}$ warming: "At $1.5^{\circ} \mathrm{C}$, approximately $70-90 \%$ of global coral reefs are projected to be at risk of long-term degradation due to coral bleaching, with these values increasing to $99 \%$ at $2{ }^{\circ} \mathrm{C} . " 13$

The Paris Agreement's temperature goal is thus, in one sense, inadequate. Even if the world achieves its more aspirational temperature goal of limiting warming to $1.5^{\circ} \mathrm{C}$, that will concededly not prevent dangerous anthropogenic interference with the climate system - it might, in fact, leave several atoll islands uninhabitable. ${ }^{14}$ It is fair to critique the goal as regrettably underprotective. In another sense, however, the Paris Agreement's temperature goal is wildly ambitious. Limiting warming to $1.5^{\circ} \mathrm{C}$, or even $2^{\circ} \mathrm{C}$, requires emissions reductions and carbon removal on an unprecedented and massive scale over very short timeframes. It is also thus fair to critique the $1.5^{\circ} \mathrm{C}$ goal as unrealistic and unachievable. The tension between these perspectives for evaluating the temperature goal - the warming that must be avoided to prevent significant harm versus the feasibility of doing so-underscores the complexity of selecting a temperature goal, as well as the intractability of the climate change challenge.

\section{B Nationally Determined Contributions}

The Paris Agreement requires parties to "prepare, communicate and maintain successive nationally determined contributions," (NDCs) or emissions reductions targets, and to "pursue domestic mitigation measures, with the aim of achieving the objectives of such contributions." 15 Parties determine their own emission reduction target; NDCs are recorded in a public registry maintained by the secretariat and must contain "information necessary for clarity, transparency and understanding." 16 Parties are required to update their NDCs every five years.

levels and related global greenhouse gas emission pathways, in the context of strengthening the global response to the threat of climate change, sustainable development, and efforts to eradicate poverty 175-312, SPM-29 (2018).

$13 \quad I d$. at 235.

14 Id.

15 Paris Agreement, supra note 5, art. 4(2).

16 To this end, NDCs must conform to instructions on their preparation, accounting, and the like set forth in decision 1/CP.21 and any relevant decisions of the Conference of the Parties serving as the meeting of the Parties to the Paris Agreement. Collectively, these decisions are often referred to as the Paris Rulebook and provide detailed guidance on implementation of the Paris Agreement, including, importantly, detailing how Parties will report on their emissions and track progress toward imple- 
These core provisions form a scaffolding for coordinating and encouraging international cooperation to achieve the Paris Agreement's temperature goal. Each party selects its own emissions target and there is no formal penalty for a party's failure to meet the emissions target identified in a previously submitted NDC. (Article 15 of the Paris Agreement establishes a mechanism to promote compliance consisting of a committee of experts but it is expressly facilitative in nature and stated to function in a non-adversarial and non-punitive manner.) The expectation and hope are that the act of complying with the required procedures of the Paris Agreement will - through the generation of reliable and shared information, reputational pressure, and financial support to developing countries - propel mitigation action by parties despite the lack of binding obligations to achieve specific emission reductions. The effectiveness of the Paris Agreement will turn on the extent to which the Paris Agreement's required processes - primarily the development and submission of NDCs - are implemented with rigor and produce transparency that encourages and disciplines countries to adopt and meet ambitious emissions targets proportionate to the reductions necessary to respect the temperature goal.

Some of the Paris Agreement's procedural requirements support ambitious mitigation action in ways that may not be immediately apparent but that could cause mandatory process to mature, over time, into obligations that become substantive. Although parties set their own emissions targets, the Paris Agreement specifies that "[e]ach Party's successive nationally determined contribution will represent a progression beyond the Party's then current nationally determined contribution and reflect its highest possible ambition." 17 While it is not yet clear what, exactly, it means for an NDC to be progressive and how it will be evaluated and enforced, robustly interpreted and applied, a requirement for progression could turn the procedural requirement to submit NDCs every five years into a meaningful substantive obligation as parties become required to reduce national emissions over time. ${ }^{18}$

Additionally, the Paris Agreement provides that parties' successive NDCs are to "be informed by the outcomes of the global stocktake." 19 The global stocktake refers to the process of "periodically tak[ing] stock of the implemen-

menting and achieving their NDC targets. Matters Relating to the Implementation of the Paris Agreement, Decs. 1/CP.24 and 3/CMA.1, UNFCC, U.N. Doc. FCCC/PA/ CMA/2018/L. 4 (2018) [hereinafter Paris Rulebook].

17 Paris Agreement, supra note 5, art. 4(3).

18 Lavanya Rajamani \& Jutta Brunnée, The Legality of Downgrading Nationally Determined Contributions under the Paris Agreement: Lessons from the US Disengagement, 29 J. OF EnvTL. L. 537-551 (2017) (explaining that it would violate the spirit of the Paris Agreement to downgrade an NDC).

19 Id. at art. 4(9). 
tation of this Agreement to assess the collective progress towards achieving the purpose of this Agreement and its long-term goals." ${ }^{20}$ The Paris Agreement requires that global stocktakes be conducted beginning in 2023 and every five years thereafter and states that "[t]he outcome of the global stocktake shall inform Parties in updating and enhancing, in a nationally determined manner, their actions and support in accordance with the relevant provisions of this Agreement, as well as in enhancing international cooperation for climate action." ${ }^{21}$ As parties' NDCs must be informed by the outcome of the (presumably most recent) global stocktake, the global stocktake process should-if robustly implemented - push successive NDCs to become more progressive if a stocktake reveals a need for further mitigation.

Finally, these binding procedures - the submission of progressive NDCs responsive to global stocktakes - are in turn supported by yet another set of binding procedures related to their implementation, the enhanced transparency framework. Under the enhanced transparency framework, all parties are required to submit, in the form of biennial transparency reports (BTRs), national GHG inventory reports (anthropogenic emissions by sources and removals by sinks of GHGs) and information necessary to track progress made in implementing and achieving NDCs. ${ }^{22}$ BTRs will be subject to a two-part review process that includes a technical expert review and a facilitative, multilateral consideration of progress. ${ }^{23}$ The technical expert review is an objective assessment and is not meant to express a political judgment or otherwise comment on the appropriateness of a party's NDC or progress. The facilitative, multilateral consideration of progress will provide an opportunity for broader comment on a party's efforts, with parties allowed to submit written questions to other parties about their BTRs followed by a working group session (open to observers) where parties can again pose questions. The enhanced transparency framework procedures are thus designed to support the NDC and global stocktake procedures by ensuring the production of accurate and comparable information and furnishing a public platform for interrogating that information, hopefully thereby supporting the development of a strong international norm of ambitious mitigation effort.

Id. at art. 14 .

Id.

Paris Agreement, supra note 5, art. 13(7).

Id. at art. 13(11). 


\section{Obligations of Conduct, Not Obligations of Result}

The Paris Agreement combines binding requirements to engage in a specified process without compelling (in the form of top-down emission targets or penalties for failure to achieve an NDC) a substantive outcome. For this reason, it has been aptly described as "an internationally legally binding agreement, containing provisions with variable legal character." ${ }^{24}$ Under the Paris Agreement, achieving emission reductions is not an obligatory commitment, but the hoped-for outcome as parties follow required procedures, norms develop around mitigation ambition, and parties are prompted to take voluntary mitigation action. The core provisions of the Paris Agreement are thus modest, in the sense that they create "obligations of conduct" as opposed to "obligations of result." 25

The Paris Agreement's mix of mandatory process and non-binding substantive outcomes reflects a negotiating compromise crucial to achieving broad participation. Because there was not support for a new, international agreement on climate change in the US Senate, the United States would not have joined any agreement that imposed new substantive obligations (such as a binding emission reduction target). President Obama was able to enter the United States into the Paris Agreement through an executive agreement (which does not require ratification by the Senate) because US obligations under the Paris Agreement were already required under the UNFCCC or authorized under domestic law.

Allowing parties to set their own non-binding NDCs also achieved broad participation by forestalling the need to decide the relative responsibilities of different parties, including developed versus developing countries. One of the chief accomplishments of the Paris Agreement is to require the submission of NDCs by developing country parties, thereby engaging all countries, regardless of development status, in global mitigation efforts. The Paris Agreement achieves this alignment of developed and developing country effort by including developing countries in the Agreement's key processes (including most importantly by requiring developing countries to submit NDCs), while continuing to recognize and make accommodations for the different circumstances of those countries.

The Paris Agreement continues to recognize that developed countries should take the lead in mitigation and support mitigation and adaptation in developing countries. The Agreement repeatedly describes higher expectations for devel-

24 Jacob Werksman, Remarks on the International Legal Character of the Paris Agreement, 34 MD. J. InT'L L. 343, 353 (2019).

25 Id. at 361 (quotation and citation omitted). 
oped country parties. For example, the Agreement explicitly recognizes that peaking of GHG emissions "will take longer for developing country Parties"26 and exhorts that developed country Parties "should continue taking the lead by undertaking economy-wide absolute emission reduction targets," while "[d]eveloping country Parties should continue enhancing their mitigation efforts, and are encouraged to move over time towards economy-wide emission reduction or limitation targets in the light of different national circumstances." 27 The Paris Agreement also states that NDCs will reflect a party's "common but differentiated responsibilities and respective capabilities, in the light of different national circumstances" 28 and at myriad junctures observes that the extent of support received from developed country Parties will be considered in evaluating developing country ambition and implementation. The Agreement also seeks to strengthen commitments by developed countries to provide financial, technology-transfer, and capacity-building support to developing countries by requiring that developed country Parties report information on the support that they have provided during the BTRs, subject to technical expert review, as part of the enhanced transparency framework. ${ }^{29}$

\section{Loss and Damage, Forestry, Adaptation, Internationally Transferred Mitigation Outcomes, and Market Mechanisms}

The submission of NDCs, the enhanced transparency framework, and the global stocktakes constitute the central structure of the Paris Agreement. Many other important issues are referenced essentially as a placeholder either to continue existing work on the issue or flagging the issue as one for future negotiation. In some instances, the Agreement commits to continue existing efforts (as with respect to addressing loss and damage, the preservation and management of forests as carbon sinks, and adaptation) and in others it identifies an issue but defers important implementation decisions to future negotiations (as with respect to the use of internationally transferred mitigation outcomes and market mechanisms).

The phrase "loss and damage" refers to harms from climate change that exceed adaptive capacity and therefore cannot be prevented or fixed. Whether and how the international climate change treaty regime should deal with loss and damage, in particular when suffered by countries that have contributed relatively little to climate change, remains a highly disputed issue. Vulnerable

\footnotetext{
Paris Agreement, supra note 5, art. 4(1).

Id. at art. 4(4).

Id. at art. 4(3).

Id. at art. 13(9).
} 
countries are keen for redress of their climate change harms while large emitters, primarily in the Global North, are wary of potential liability for claims of loss and damage. The Paris Agreement continues preexisting international efforts to address loss and damage (for example, through insurance and risk transfer) and situates them within the Paris Agreement. Article 8 provides that the Warsaw International Mechanism for Loss and Damage is subject to the authority and guidance of the Paris Agreement's COP and exhorts parties to "enhance understanding, action and support ... on a cooperative and facilitative basis with respect to loss and damage." ${ }^{30}$ Reflecting developed country skittishness about potential liability for loss and damage, the decision adopting the Paris Agreement admonishes, however, that Article 8 "does not involve or provide a basis for any liability or compensation." ${ }^{31}$

The management of forests to maximize carbon sequestration has also long been a focus of the international climate change treaty regime. The Paris Agreement encourages Parties to conserve and enhance sinks and reservoirs of GHGs, primarily forests, through existing frameworks such as the Warsaw Framework for REDD+. ${ }^{32}$ The Warsaw Framework for REDD+ was adopted at COP19 in December 2013 and provides methodological and financing guidance for the implementation of REDD+ activities, which include reducing emissions from deforestation and forest degradation, the conservation of forest carbon stocks, sustainable management of forests, and the enhancement of forest carbon stocks. The Paris Agreement thus blesses continued work through existing processes to promote the conservation and enhancement of sinks and reservoirs, most notably forests, without materially changing the treaty regime's approach to the issue.

The Paris Agreement's approach to adaptation (or preparation for the impacts of climate change as opposed to efforts to reduce climate change (mitigation)) likewise builds on prior efforts, while also incorporating new and potentially powerful transparency related to adaptation. The agreement announces a global goal on adaptation ${ }^{33}$ and encourages parties to strengthen their cooperation on enhancing action on adaptation, taking into account the existing Cancun Adaptation Framework. ${ }^{34}$ The Paris Agreement requires that parties engage "as appropriate" in adaptation planning processes and imple-

Id. at art. 8 .

Decision 1/CP.21, supra note 11, art. 5.

Paris Agreement, supra note 5, art. 5.

33 Id. at art. 7(1) (announcing the global goal of "enhancing adaptive capacity, strengthening resilience and reducing vulnerability to climate change, with a view to contributing to sustainable development and ensuring an adequate adaptation response in the context of the temperature goal").

${ }_{34}$ Id. at art. 7(7). 
mentation and provides that parties should submit and periodically update adaptation communications describing adaptation progress and needs. ${ }^{35}$ Global stocktakes will evaluate adaptation, including by reviewing the adequacy and effectiveness of adaptation and also evaluating the support provided for adaptation and reviewing the overall progress made in achieving the global goal on adaptation. ${ }^{36}$

With respect to loss and damage, forestry, and adaptation, the Paris Agreement creates continuity, largely recommitting to the continuation and strengthening of existing initiatives. With respect to another important issue central to the operation of the Paris Agreement, the question of how Parties can use emission reductions achieved through non-domestic mitigation to fulfill their own NDCs and the operation of an international carbon market, the Paris Agreement essentially serves as a placeholder, deferring difficult decisions to future negotiations.

Article 6(2) of the Paris Agreement approves, in concept, the idea that Parties can use internationally transferred mitigation outcomes to achieve NDCs and clarifies that such arrangements are to be voluntary, authorized by participating Parties, and conform to some general guidelines (for example, use robust and transparent accounting and avoid double counting) ${ }^{37}$ Article 6(4) contemplates the establishment of an international carbon market and creates a mechanism, to be overseen by a new body designated by the COP, which will develop rules, modalities, and procedures for its implementation. Article 6(4) instructs that one aim of the market shall be to achieve an overall mitigation in global emissions, directs that a share of proceeds from its operation be put toward administrative expenses and supporting adaptation in vulnerable developing countries, and specifies that emissions reductions should not be counted toward achievement of both the host Party's NDC and another Party's NDC. The decision adopting the Paris Agreement further states that emissions reductions created by Article 6(4) must be "additional to any that would otherwise occur," referencing the idea that proceeding with business as usual should not have produced the reductions..$^{38}$

But the Paris Agreement leaves decisions about crucial details for the implementation of both country-to-country exchanges and the operation of an international carbon market, including what will count as an internationally transferred mitigation outcome and how additionality will be evaluated, to be negotiated at future meetings of the COP. Ultimately, the country-to-country

\author{
Id. at art. 7(9)-(12). \\ Id. at art. 7(14). \\ Paris Agreement, supra note 5, at art. 6 (2). \\ Decision Adopting the Paris Agreement, supra note 11, at 938.
}


exchanges of mitigation outcomes and a functional international carbon market will likely be a key component for the achievement of NDCs, particularly as ambition increases, underscoring the central importance of the work yet to be done.

\section{EVOLUTION OF THE CLIMATE CHANGE TREATY REGIME}

The Paris Agreement embodies the modern climate change treaty regime. Some understanding of the evolution of the climate change treaty regime nonetheless provides important context for understanding the Paris Agreement, including most notably its marriage of non-binding substantive elements and binding procedures.

The Paris Agreement is a legal instrument negotiated under the UNFCCC. The UNFCCC establishes the general system of governance that anchors the climate change treaty regime and, like the Paris Agreement, achieved universal participation. The UNFCCC can perhaps best be understood as an international agreement to agree to solve a common problem, climate change. The UNFCCC states the broad goal of "stabilization of greenhouse gas concentrations in the atmosphere at a level that would prevent dangerous anthropogenic interference with the climate system," creates a process for parties to submit national emission inventories, and requires developed country parties identified in Annex I of the Agreement to submit national mitigation plans and emission inventories. ${ }^{39}$

The UNFCCC also articulates principles to guide international cooperation to address climate change. ${ }^{40}$ One key principle in the UNFCC is the idea that countries have common but differentiated responsibilities with respect to climate change. The concept captures the idea that all countries should work to solve climate change, but that their relative contributions to that effort must acknowledge differences in terms of the volume of emissions they have contributed to the problem and their development and capacities. The concept is particularly salient for thinking about the relative obligations of the Global North and Global South.

The UNFCCC's articulation of common but differentiated responsibilities is of continuing import because subsequent negotiations have failed to produce agreement on the meaning of the concept in practice (as applied, for example, to determine the appropriate mitigation obligations of different countries). Indeed, the practical meaning of common but differentiated responsibilities

39 UNFCCC, supra note 3, art. 2, 4.

$40 \quad$ Id. at art. 3. 
(sometimes referred to as differentiation) has proved to be the stickiest wicket in development of international cooperation on climate change. The UNFCCC asserts that parties should act "in accordance with their common but differentiated responsibilities and respective capabilities." ${ }^{41}$ It goes on to assert that "the developed country Parties should take the lead in combating climate change and the adverse effects thereof," 42 having explained in the preamble that "the largest share of historical and current global emissions of GHGs has originated in developed countries, that per capita emissions in developing countries are still relatively low and that the share of global emissions originating in developing countries will grow to meet their social and development needs." 43 The agreement further emphasizes the development prerogative, stating that "Parties have a right to ... sustainable development" and that "Parties should cooperate to promote a supportive and open international economic system that would lead to sustainable economic growth and development in all Parties, particularly developing country Parties." ${ }^{44}$ Applying this principle to assign obligations for emission reductions has proved fraught.

As discussed above, by allowing countries to set their own substantive emission targets, the Paris Agreement avoids the need to agree upon the relative responsibility of parties for mitigation. This reflects, in part, the great difficulty of translating the concept of common but differentiated responsibilities into practice. Indeed, disputes about the nature of common but differentiated responsibilities are key to understanding not only the structure of the Paris Agreement, but also why the agreement that immediately preceded it - the Kyoto Protocol- proved to be a dead end.

Negotiations immediately following the UNFCCC produced the Kyoto Protocol which set top-down binding GHG emission targets, termed quantified emission limitation and reduction objectives, which were typically around 5\% below 1990 levels for the first compliance period (2008-2012) and 18\% below 1990 levels in the second compliance period (2013 to 2020). ${ }^{45}$ These

41 Id. at art. 3.

$42 \quad I d$. at art. 3.

43 Preamble to the UNFCCC, supra note 3.

44 UNFCCC, supra note 3, art. 3.

45 That the world initially adopted this top-down approach to controlling GHG emissions likely reflects, in part, a reflexive effort to replicate the success of the world's approach to controlling the emission of ozone-depleting substances as embodied in the Vienna Convention for the Protection of the Ozone Layer (which, like the UNFCCC, set forth a very general agreement to agree to reduce the emission of ozone-depleting substances) and the Montreal Protocol on Substances That Deplete the Ozone Layer (which, like the Kyoto Protocol, imposed top-down binding emission limits). Notably, some substitutes for the ozone-depleting substances being phased out under the Montreal Protocol are also potent GHGs. The Montreal Protocol has since been 
targets were only imposed on developed country parties identified in Annex I to the UNFCCC who ratified the Kyoto Protocol. The Kyoto Protocol established a cap and trade regime that incorporated flexibility mechanisms through which Annex I parties could meet their emissions targets by purchasing emission credits through International Emissions Trading (Article 17), supporting Joint Implementation projects in other developed countries to obtain Emission Reduction Units (Article 6), or obtain Certified Emission Reductions by supporting projects in developing countries through the Clean Development Mechanism (Article 12). ${ }^{46}$

That the initial interpretation of the UNFCCC's common but differentiated responsibilities imposed no emission targets on developing countries ultimately became the downfall of the Kyoto Protocol's top-down approach. The Kyoto Protocol never achieved universal participation. The US never ratified the Kyoto Protocol (primarily out of concern that no emission reductions targets were required from developing countries), Canada withdrew, some important Annex I countries did not submit new emission targets in the Kyoto Protocol's second compliance period (Japan, New Zealand, Russia), and developing country parties were never subject to emission targets. Moreover, many have called into question the volume of emission reductions ultimately achieved by the Kyoto Protocol.

The climate change treaty regime has since evolved into the bottom-up approach of the Paris Agreement described above. The significance of the Kyoto Protocol to international climate change mitigation efforts is debated. One area of learning under the Kyoto Protocol that will likely prove important is how the experience implementing the Clean Development Mechanism under the Kyoto Protocol—which has been subject to great criticism-will support and inform the development of rules relating to carbon markets under Article 6(4) of the Paris Agreement. And one issue presently being negotiated is whether and how to merge the Kyoto Protocol, in particular the potential migration of projects under the Clean Development Mechanism and Joint Implementation, into the structure of the Paris Agreement.

\section{CONCLUSION}

The takeaway from the current status of the international climate change treaty regime is both hopeful and worrisome. It has taken an exhausting nearly 30 -year process to get us to what is, in some ways, a new starting

amended, through the Kigali Amendment, to limit the reliance on those GHG-heavy substitutes.

46 Kyoto Protocol, supra note 4, at arts. 6, 12, 17. 
point in the form of the Paris Agreement. And, as described above, it will take significant energy, focus, and commitment to successfully implement the Paris Agreement. What we must hope is that this time we are at the bottom of a ladder with more rungs, one that, if we climb, it will lead to effective international cooperation on mitigation. 